\section{B A Institute of \\ YK Business Administration \\ 六下 \\ Karachi \\ Leadership and Ideas for Tomorrow}

Business Review

Volume 15 Issue 2 July-December 2020

$1-15-2021$

\title{
Education and life satisfaction: A marginal mediation analysis
}

\author{
Faiza Hassan \\ University of Malakand, Pakistan Institute of Development Economics, Pakistan \\ Hafsa Hina \\ Pakistan Institute of Development Economics, Pakistan \\ Abdul Qayyum \\ Pakistan Institute of Development Economics, Pakistan
}

Follow this and additional works at: https://ir.iba.edu.pk/businessreview

Part of the Economics Commons

c) (i)

This work is licensed under a Creative Commons Attribution 4.0 International License.

\section{Recommended Citation}

Hassan, F., Hina, H., \& Qayyum, A. (2021). Education and life satisfaction: A marginal mediation analysis. Business Review, 15(2), 1-26. Retrieved from https://doi.org/10.54784/1990-6587.1058

This article is brought to you by iRepository for open access under the Creative Commons Attribution 4.0 License and is available at https://ir.iba.edu.pk/businessreview/vol15/iss2/1. For more information, please contact irepository@iba.edu.pk. 


\title{
Education and life satisfaction: A marginal mediation analysis
}

Faiza Hassan • Hafsa Hina • Abdul Qayyum (Late)

\begin{abstract}
The current micro-level study explores the impact of education on life satisfaction of individuals in Pakistan via six mediating factors that are health, employment status, marital status, number of children, the scale of income and freedom of choice. The differences based on gender, marital status and the scale of income are also analyzed by using data from Wave 6 (2010-2014) of the World Values Survey. The marginal mediation technique by Barrett (2018) is used. It is observed that education plays a significant role in affecting life satisfaction. The channels of health, freedom and scale of income are found significant in the analysis of the full sample. Different paths are found operative for opposite genders. Comparison based on the scale of income shows that more channels are found effective for the middle class as compared to rich and poor.
\end{abstract}

Keywords Education · Life satisfaction · Marginal mediation technique

\section{Introduction}

The concept of wellbeing, life satisfaction and happiness has remained in the philosophy of economics since its inception as a subject. Although the distinction between wealth and happiness was recognized by classical economists, the subject remained and became more focused on utility, wealth, GDP and its growth. It was believed that more money, wealth and consumption means more wellbeing and happiness to individuals and nations.

The seminal work of Easterlin (2004) and Scitovsky (1976) changed the focus of economists from wealth to happiness. In contrast to Pigou's dictum, it was

Faiza Hassan

University of Malakand, Pakistan Institute of Development Economics-Pakistan

E-mail: faizajafar86@gmail.com

Hafsa Hina

Pakistan Institute of Development Economics-Pakistan

Abdul Qayyum

Pakistan Institute of Development Economics-Pakistan

(C)Hassan, F., Hina, H. and Qayyum, A. 2020 
concluded that richer countries were not happier than poorer countries. Also, it was shown that despite the rapid increase in income there was not much increase in happiness of the US over time (1946 to 1970). The Easterlin paradox and Scitovsky (1976) could not draw the interest of many researchers and the subject remained dormant until 1990. These two eminent researchers made further contributions in 1995 and 1992 respectively, that grabbed the attention of many economists, and as a result, a new branch of economics emerged with the name 'Economics of Happiness'.

Education is a much-recognized factor in improving quality of life and thereby increasing life satisfaction. Many educationists and economists are in favour of public expenditure on education because education increases the overall quality of life. Education enhances life satisfaction not only through its monetary rewards but also because of its positive impact on almost every aspect of life.

The literature on education and life satisfaction can be divided into two distinct categories. One group of researchers found that education is positively associated with life satisfaction because of its positive economic, social and psychological impact on individuals (Blanchflower and Oswald 1994; Tella et al 2003; Hayo and Seifert 2003; Chen 2012). The second cluster of studies revealed no or a negative association between the two, particularly after some threshold level of education (Clark and Oswald 1996; Helliwell 2003; Inglehart et al 2008).

In literature, income is the most acknowledged return of education. The pioneering work to establish the relationship between education and income is of Mincer (1974) and is popularly known as the Mincerian Equation. Similarly, it is depicted that an additional year of schooling results in increased income (Angrist and Keueger 1991; Leigh and Ryan 2008). However, it is not only the monetary rewards through which education leads to higher life satisfaction but there are some other significant mediating factors (Brighouse 2006; Michalos 2008). It is explored that in addition to income, education has a significant impact on one's health, marital life, family size, and chances of getting employment (Oreopoulos and Salvanes 2011).

Education and mental and physical health are observed to be positively and significantly associated (Silles 2009; Powdthavee 2010). Mincer (1974) and Kettunen (1997) recorded that individuals with higher education have comparatively fewer chances of being unemployed and if unemployed they do not remain unemployed for longer periods. Furthermore, educated individuals with prestigious jobs seem more attractive for marriage and have better marital choices (Chiappori et al 2009; Lafortune 2013). It is also witnessed that educated people have more stable marriages and hence a lower divorce rate (Oreopoulos and Salvanes 2011). There is empirical evidence that education has a negative impact on family size (Sander 1992; Martin 1995). Educated women have a greater opportunity cost of being out of the labour market for the child-rearing period which discourages them from having a large family.

On the other hand, vast literature about defining the determinants of happiness or life satisfaction in economics illustrates that income, education, health, employment, marital status, number of children and freedom of choice are important predictors of life satisfaction (Martin 1995; Layard 2004; Yang 2008; Verme 2009; Layard et al 2013). 
Verme (2009) observed that freedom of choice and control over life is the dominant predictor of life satisfaction rather than any other factor such as income, health, employment, marital status or religion. However, in literature, the mediating effect of freedom of choice and control over life in relation to education and life satisfaction has not yet been studied.

Although literature acknowledges the role of education in affecting health, employability, marital status, family size and income of individuals and it is also well established that all these factors along with education are the determinants of life satisfaction. However, literature only considers the direct effect of education on life satisfaction. Its indirect effect through its ability to affect health, employment status, income, marital status and number of children is not explored. All the previous studies except Powdthavee (2010) investigated the effect of education on life satisfaction by taking these factors as control variables in the equation. Powdthavee (2010) contributed to literature by pointing out that the use of the single-equation model ignores the fact that the factors that are taken as control variables are the function of education themselves. Therefore, the multiple mediation model is proposed to properly investigate the role of intermediating variables through which education affects life satisfaction.

The purpose of the current study is to find the direct and indirect impact of education on life satisfaction in the context of Pakistan as a case of a developing country. The indirect effects of education on life satisfaction are analyzed through six mediating factors namely health, freedom of choice and control over life, marital status, number of children, employment status and scale of income. The analysis is also repeated for different categories based on gender and scale of income.

This study is the first attempt with reference to Pakistan that aims to investigate the relationship between education and life satisfaction and tries to specify the channels through which education indirectly affects life satisfaction. This analysis is important for various reasons. Firstly, it empirically evaluates the general perception that education enhances life satisfaction in a particular economy or segment of the economy. Secondly, the study of the indirect effect of education on life satisfaction addresses the question; why education is important and what are the channels through which it increases life satisfaction. Thirdly, it is worthwhile to know the paths that are effective and the ones that are broken and unable to translate the good of education into life satisfaction. Fourthly, the analysis of differences in the impact of education on life satisfaction based on gender and scale of income will help policymakers to decide if special focus is required on a particular segment of society.

The paper is organized in different sections. Section 2 reviews literature, section 3 is about model and estimation methodology, section 4 explains the estimation results. Section 5 is devoted to report conclusions and section 6 is about policy implications and presents ideas for future research. 


\section{Literature Review}

Happiness, life satisfaction and subjective wellbeing are words that are used synonymously in economics. Veenhoven (1996) presented a detailed insight into definition, measurement, reliability and validity of data about life satisfaction. Similarly, Veenhoven (2012) provided a detailed discussion about definition and measurement of happiness, life satisfaction and subjective wellbeing.

There are numerous studies in literature that describe the positive association between education and life satisfaction. Blanchflower and Oswald (1994) established that education affects happiness independently of income while studying happiness in the US and UK. Rojas (2004) following the domains-of-life approach attempted to study the wellbeing of individuals. It was established that education is important and contributed positively in almost every domain of life. Seven main domains were identified i.e. health, economics, job, personal, family, friendship and community environment. In the study of Bukenya et al (2003) education is found to have a significantly positive effect on the quality of life in a sample of 2000 individuals of West Virginia. Furthermore, individuals with higher education have a higher probability of having a better quality of life as compared to individuals with a low level of education. Similarly, empirical studies of Tella et al (2003); Hayo and Seifert (2003); Castriota (2006); Chen (2012); Botha (2014); Ferrer-i Carbonell (2005); Frey and Stutzer (2000) and many others concluded the same that education is a significant factor in explaining higher life satisfaction.

In literature, income is the most acknowledged return of education. Mincer (1974) attempted to model the effect of investment in human capital (education) on earnings. As a result, the most widely used mincerian equation emerged that links earnings with years of schooling and experience. The Mincerian equation is used by numerous studies for a large number of countries and different demographic groups. Card (1999) reviewed the empirical work of the link between education and earnings. The studies are categorized into two groups; studies that used OLS and those that used the instrumental variable technique, estimates of all studies are listed in the paper. The review concluded that the added year of schooling results in a $7-12 \%$ increase in income, keeping in view the other affecting factors like; ability, family background and intelligence.

The recent study of Psacharopoulos and Patrinos (2018) reviewed studies on returns of investment in education. The review covers studies from 1950 to 2014, 139 countries and 1120 estimates. The two main methods discussed in the review were Mincerian earnings equation which describes education-earnings relationship and full discounting method. It is concluded on the basis of 705 estimates of the Mincerian function that every added year of schooling means 8.8 percent higher earnings. It is also summarized that private returns to education for female are 2\% higher than male. Angrist and Keueger (1991) illustrated that extra schooling has a positive impact on earnings, interestingly they found that even small differences in schooling have significant differences in earnings. They found that individuals who have to attend more schooling because of their quarter of birth and the compulsory schooling laws have greater earnings. Similarly, Harmon and Walker (1995) and Leigh and Ryan (2008) also support the 
positive relationship between income and years of schooling both by OLS and instrumental variable estimation technique.

It is also a well-established fact that income is significantly and positively associated with subjective wellbeing or life satisfaction or happiness (Blanchflower and Oswald 1994; Yang 2008; Headey et al 2008; Selim 2008). While Cuñado and de Gracia (2012); Castriota (2006); Checchi (2006); Powdthavee et al (2015); Campbell (1981); Witter et al (1984) show that part of the relationship between education and social wellbeing exists because of the covariance of education and income.

However, many studies established that it is not only the monetary rewards through which education leads to higher life satisfaction but there are some other mediating factors (Brighouse 2006; Michalos 2008). This argument is augmented by the empirical research in which education is shown to be positively associated with life satisfaction even after controlling for income (Blanchflower and Oswald 2004; Gerdtham and Johannesson 2001; Selim 2008; Shin and Inoguchi 2009). It is observed that it is not only income but also the effect of education on health, marital life, family size, and chances of getting employment that leads to higher life satisfaction (Layard 2004; Yang 2008). It is established that individuals with better education on average have better health, fewer chances of remaining unemployed and better marital life resulting in a lower divorce rate. Mostly income together with health, employment and marital status are attributed as factors that mediate between education and subjective wellbeing (Chen 2012).

Silles (2009) and Powdthavee (2010) observed that education and mental and physical health are positively and significantly associated. Cutler and LlerasMuney (2006) discussed and reviewed different existing theories and possibilities about the link between education and health. Accordingly, some of the explanations for the link between education and health are that better education means increased income, better occupational status and environment that helps in preserving better health.

Educated people can get quick access to new information and technology to prevent or treat a disease and they are also quick to respond to health campaigns or new guidelines. Moreover, individuals with higher education have peer recognition for good habits regarding health e.g. exercise, routine checkups, blood pressure and sugar controls and face peer disapproval for bad habits e.g. smoking, drinking and drugs etc. which helps them to maintain better health. Another hypothesis regarding education and health is that more educated people are more risk-averse and therefore maintain better health. Similarly, it is also explained that education increases a person's rank in society which means that they have more control over their lives and less influenced by negative emotions which people at lower ranks face e.g. depression, anxiety and hostility.

Education also increases the ability to think differently and to make better decisions due to better information and cognition. Easterlin (2004) described the relationship between health and life satisfaction. Based on his work and a large survey results by sociologists, psychologists and American survey data, the study termed health an important factor in defining life satisfaction and rejected the setpoint theory by psychologists and concluded that adverse changes

Business Review: (2020) 15(2):1-26 
in health have lasting negative impacts on happiness. Similarly, Appleton and Song (2008) based on survey data of 7000 individuals from China reported that ill-health adversely affects subjective wellbeing and people who are satisfied with their health status have more chances of being satisfied with their life.

Blanchflower and Oswald (1994) and Albert and Davia (2005) proposed that education increases subjective wellbeing because of job quality and opportunity of getting interesting jobs. Mincer (1991) and Kettunen (1997) recorded that individuals with higher education have comparatively fewer chances of being unemployed and if unemployed they do not remain unemployed for long periods. On the other hand, it is also established that employment status affects life satisfaction. For example, Grün et al (2010) attempted to compare the life satisfaction of people in two different time periods; when they were unemployed and after they got employment with consideration of job quality. It was found that people without a job are less satisfied with their lives as compared to the situation when they get jobs, even people with bad job quality were found more satisfied than what they were during the unemployment period. The study could not find a single factor or combination of characteristics that make a job, less preferable than remaining unemployed. However good quality jobs increase life satisfaction more than a bad quality job. Similarly, Hassall et al (2004) also concluded that low wage earners are better off than unemployed in terms of life satisfaction. Layard (2004) reported that "human happiness is more affected by whether or not one has a job than by what kind of job it is". On the contrary, Dockery et al (2003) reported based on Australian household panel data that remaining in a job that has less job satisfaction is more unfavourable for life satisfaction as compared to remaining without a job.

It is observed by many studies that individuals with higher education and prestigious jobs seem more attractive for marriage and have better choices (Chiappori et al 2009; Lafortune 2013). It is also witnessed that educated people have more stable marriages and hence have a lower divorce rate (Oreopoulos and Salvanes 2011). Blanchflower and Oswald (1994) illustrated that self-reported wellbeing is greater for those who are married as compared to unmarried people and also it is greater for highly educated people and low among less educated. The analysis was based on 100,000 individuals from the US and UK. Helliwell (2003) reported the same that married individuals on average report higher life satisfaction than unmarried.

With relation to the impact of family size, there is empirical evidence that education has a negative impact on family size (Sander 1992; Martin 1995) because more educated women have a higher opportunity cost of being out of the labour market for the time-period of child-rearing. Haller and Hadler (2006) reported children as positively contributing factor of life satisfaction. While studies of Tella et al (2003) and Smith (2003) observed that in the UK and US children have a negative impact on life satisfaction.

Verme (2009) states that "a variable that measures freedom of choice and the locus of control is found to predict life satisfaction better than any other known factor such as health, employment, income, marriage or religion, across countries and within countries". Although the importance of freedom and control over life is recognized as an important factor in determining life satisfaction 
it is not studied as a mediating factor in relation to education and life satisfaction.

Cuñado and de Gracia (2012) analyzed the relationship of education and life satisfaction and concluded that education is contributing more to the happiness of poor as compared to rich income groups.

However, many studies also reported no effect or negative effect of education on subjective well-being or life satisfaction. For example, Headey and Wooden (2004); Inglehart and Klingemann (2000); Clark and Oswald (1996) and others observed that no significant relationship exists between education and wellbeing. Inglehart and Klingemann (2000) performed a cross-national analysis consisting of 64 societies, the study concluded that society's education does not have a significant impact on its overall wellbeing. Similarly, Helliwell (2003) found no impact of increasing level of education on wellbeing both on a national and individual level when perceived trust, income and health are considered in the model; based on data of 50 countries from three successive WVS. While the results of Clark and Oswald (1996) showed a strong negative relationship between education and life satisfaction of workers when income is held constant, and higher aspirations due to higher education might be the reason for the negative relationship. Ferrante (2009) also reported a negative relationship between education and life satisfaction.

Although literature acknowledges that education has the ability to affect individuals health, employability, marital status, family size and income and these factors are all reported as determinants of life satisfaction along with education, however, in most of the studies the above-mentioned factors i.e. health, employability, marital status, family size, income and education are included in a single equation model of life satisfaction. The problem with using a single equation model for finding the relationship between education and life satisfaction is that it ignores the ability of education to effect the control variables like health, employment status and others, so the indirect effect of education through these channels are not properly analyzed. Powdthavee et al (2015) is the only study that attempted to analyze the indirect effect of education on life satisfaction in Australia by utilizing structural equation model in contrast to all previous studies which used a single equation model.

The current study contributes to literature with reference to developing countries like Pakistan. It identifies how outcomes of education affect life satisfaction in a developing country and how these are different in their behaviour in comparison with a developed country observed in the study of Powdthavee et al (2015). This study also investigates whether education is a contributing factor to life satisfaction for all social classes; poor, middle class and higher class or it is only important in the life of poor in Pakistan. Furthermore, the study also includes freedom of choice and control over life as a mediating factor in education and life satisfaction model for the first time. 


\section{Methodology}

In the literature of economics, the relationship between education and life satisfaction is mostly analyzed by the single equation model, where the effect of education is modelled by including education as an explanatory variable along with other control variables in the life satisfaction or happiness equation. For example, Botha (2014); Chen (2012); Blanchflower and Oswald (2004); Hayo and Seifert (2003); Easterlin (2004) and many others used the single equation model like the one given below as an example for analyzing the impact of education on life satisfaction.

$$
\mu_{i}=\alpha+\beta E D U_{i}+\gamma Z_{i}+\varepsilon_{i}
$$

$$
i=1,2 \ldots . . I
$$

where $u$ represents the response of happiness or life satisfaction question which can take values from 1 to $10 . E D U$ represents education of an individual, $Z$ is a vector of control variables for example age, health, marital status etc and $\varepsilon$ is a random error term while $i$ represents the $i$ th individual.

The problem with the use of the single-equation model to analyze the relationship between education and life satisfaction is that the variables that are usually included as control variables like health and income are the functions of education themselves. The ability of education to impact the control variables in these models is completely ignored.

Powdthavee et al (2015) was the first attempt to analyze the indirect effect of education on life satisfaction. The study reports that although the researchers identified that ignoring the indirect effect of education on life satisfaction will underestimate the contribution of education in explaining life satisfaction, still no efforts are made to correct this estimation bias. Powdthavee et al (2015) suggested the use of a multiple mediation model in order to capture the indirect effect of education on life satisfaction in addition to its direct effect.

Following the suggestions of Powdthavee et al (2015), the current study analyzes the direct as well as indirect effects of education on life satisfaction in Pakistan through six mediating factors. The impact of education on life satisfaction, its direct and indirect effect can be summarized in the following sequence of equations proposed by Powdthavee et al (2015) for capturing the indirect effect of education on life satisfaction and based on statistical tools developed by the Judd and Kenny (1981) and Baron and Kenny (1986) for performing mediation analysis.

$$
\begin{gathered}
L S_{i}=\alpha+c E D U_{i}+\theta_{0} Z_{i}^{\prime}+\mu_{1 i} \\
L S_{i}=\beta_{0}+\Sigma_{s=1}^{6} b_{s} M_{s i}+c^{\prime} E D U_{i}+\theta_{0} Z_{i}^{\prime}+\mu_{0 i} \\
M_{1 i}=\alpha_{1}+\alpha_{1} E D U_{i}+\theta_{0} Z_{i}^{\prime}+\mu_{1 i}
\end{gathered}
$$




$$
M_{6 i}=\alpha_{6}+\alpha_{6} E D U_{i}+\theta_{6} Z_{i}^{\prime}+\mu_{6 i}
$$

where $L S$ stands for life satisfaction. Mediating factors that include income, health, employability, marriage, number of children and freedom of choice and control over life are represented by $M_{s}$. The variable $E D U$ represents education while $Z_{i}^{\prime}$ denotes control variables which include age and age square. The theoretical model can be visualized by the following path diagram.

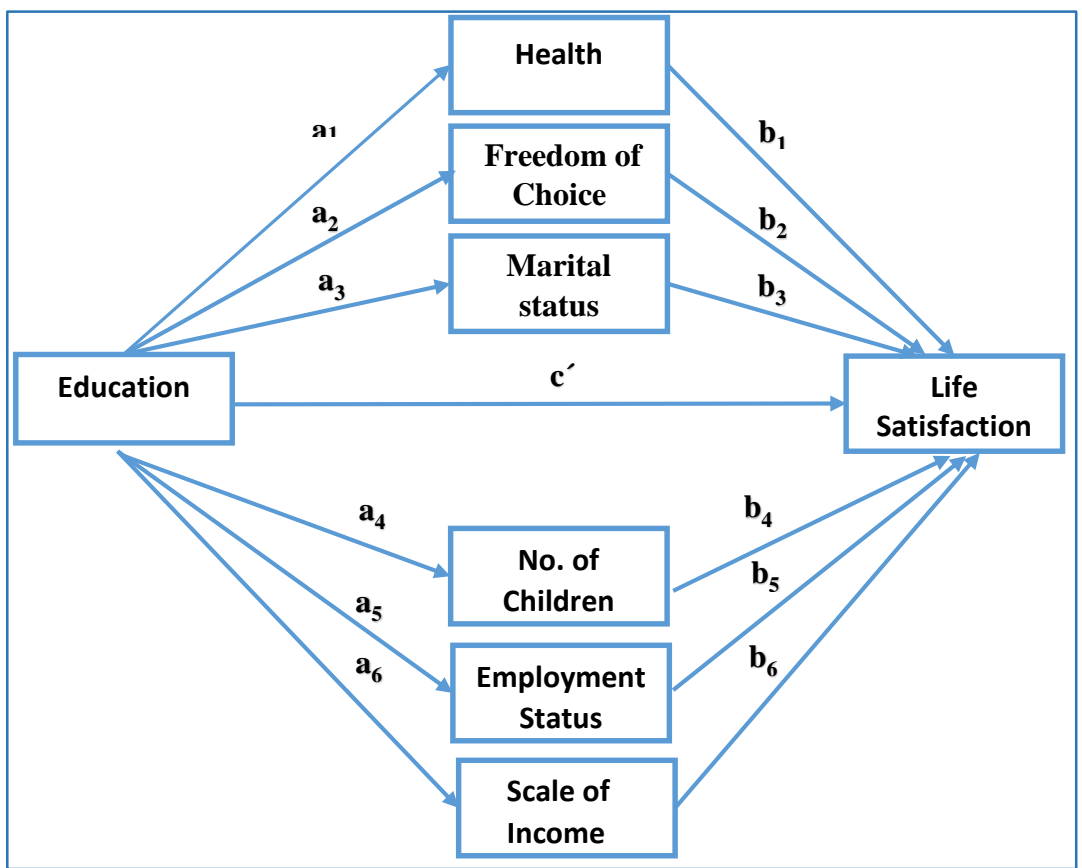

Fig. 1: Education and life satisfaction a multiple mediation model

\subsection{Estimation methodology}

Literature establishes that the association between dependent and independent variables will be different by the addition of the third variable if the third variable is a mediating factor i.e. it does not only depend on the independent variable but has the ability to affect the dependent variable of the model (Baron and Kenny 1986; MacKinnon and Dwyer 1993; Shrout and Bolger 2002). The effect of the independent variable on the dependent variable through the mediating variable was termed as the indirect effect by Shrout and Bolger (2002).

In order to decide about the estimation technique we follow the study of Iacobucci (2012). Iacobucci (2012) treats the variables that are defined on 5, 7 and 9 point scale as continuous and the variables that have binary responses or different brands or ethnicities are considered as categorical variables. In our model, the predictor and outcome variables are continuous and the mediator 
variables are mix; some are continuous and employment status and marital status are binary mediators.

The method of marginal mediation analysis proposed by Barrett (2018) is found best to analyze the model. Marginal Mediation Analysis integrates the method of Average Marginal Effects (AMEs) proposed by Bartus (2005) in mediation analysis. Marginal mediation is the latest approach to deal with binary mediators and/ or binary outcomes and to get effect size of each mediator without any interpretability issues.

Barrett (2018) discussed the existing methods and their limitations to deal with categorical outcomes and mediators. It is illustrated that the marginal mediation analysis makes the interpretation of indirect effects more meaningful and simple in the models which were previously considered problematic (models with categorical mediators and outcomes). It is elaborated that Average Marginal Effects (AMEs) are robust in case of model misspecification and unobserved heterogeneity and generally applicable to any type and mix of models. The following steps will be followed to estimate the direct and indirect effect of education on life satisfaction as proposed by the method of Marginal mediation by Barrett (2018).

Step 1. Estimation of equation 2 to 8 through a generalized linear model (glm) keeping in view the type of outcome variable in each equation and using family binomial for the equations where the outcome is binary. The regressions in this step will estimate a total of six 'a' paths describing the effect of education on mediators, it will also estimate six ' $b$ ' paths unfolding the effect of potential mediators on life satisfaction and estimate the $c^{\prime}$ path.

Step 2. The novelty of Marginal mediation analysis is in post-estimation steps. After estimation of all paths, the next step is to find average marginal effects (AMEs) for each path. All 'a' paths have a continuous predictor so we will use the following formula:

$$
A M E_{\alpha_{s}}=\frac{1}{n} \sum_{i=1}^{n} f\left(\alpha_{s} E D U\right)
$$

where 's' varies from 1 to 6 presenting 6 mediators, $i$ represents a number of observations and $E D U$ is used to symbolize education. So for first a path that is $a_{1}$, the path between education and health, the average marginal effect is given by $A M E_{\alpha_{1}}$ which can be written as:

$$
\begin{gathered}
A M E_{\alpha_{1}}=\frac{1}{n} \sum_{i=1}^{n} f\left(\alpha_{1} E D U\right) \\
A M E_{\text {health }}=\frac{1}{n} \sum_{i=1}^{n} \frac{f\left(\alpha_{1} E D U_{1}\right)-f\left(\alpha_{1} E D U_{2}\right)}{2 h}
\end{gathered}
$$

where $\alpha_{1} E D U_{1}$ and $\alpha_{1} E D U_{2}$ are given by the following matrices:

$$
\left(\begin{array}{ccc}
\alpha_{1} E D U_{11}+h & \theta_{1} \text { Age }_{12} & \theta_{2} \text { Age } 2_{13} \\
\alpha_{1} E D U_{21}+h & \theta_{1} \text { Age }_{22} & \theta_{2} \text { Age } 2_{23} \\
\cdot & & \\
\cdot & & \\
\alpha_{1} E D \dot{U}_{n 1}+h & \theta_{1} \text { Age }_{n 2} & \theta_{2} \text { Age } 2_{n 3}
\end{array}\right)
$$




$$
\left(\begin{array}{ccc}
\alpha_{1} E D U_{11}-h & \theta_{1} \text { Age }_{12} & \theta_{2} A g e 2_{13} \\
\alpha_{1} E D U_{21}-h & \theta_{1} \text { Age }_{22} & \theta_{2} A g e 2_{23} \\
\cdot & & \\
\cdot & & \\
\cdot & & \\
\alpha_{1} E D U_{n 1}-h & \theta_{1} A g e_{n 2} & \theta_{2} A g e 2_{n 3}
\end{array}\right)
$$

Matrices given above are the predicted changes in outcome due to very small changes $h$, where $h=110^{-7}$. In the same manner, AMEs for all 'a' paths will be found.

Step 3. Then we have to find AMEs for ' $b$ ' paths. Same procedure as described in step 2 will be followed, except for ' $b$ ' paths from marital status and employment status to life satisfaction as they are binary variables. The following changes will be incorporated in addition to the same margin method described in step 2.

$$
A M E_{M S \rightarrow L S}=A M E_{b_{3}}=\frac{1}{n} \sum_{i=1}^{n}\left[F\left(b_{3} M S \mid M S=1\right)-F\left(b_{3} M S \mid M S=0\right)\right]
$$

where $M S \rightarrow L S$ represents a path from marital status to life satisfaction, $b_{3}$ is the name of this path and estimate calculated in step $1 . M S=1$ represents a married person while $M S=0$ represents a person who is single.

$$
A M E_{E m p \rightarrow L S}=\frac{1}{n} \sum_{i=1}^{n}\left[F\left(b_{5} E m p \mid E m p=1\right)-F\left(b_{5} E m p \mid E m p=0\right]\right.
$$

where $E m p \rightarrow L S$ is a path from employment to life satisfaction, $b_{5}$ is the name of this path and estimate calculated in step 1. $E m p=1$ represents an employed person while $E m p=0$ represents a person who is unemployed.

Step 4: The indirect effects are the product of AMEs of ' $a$ ' and 'b' paths. For example, the indirect effect for health is AME of the path from education to health (a1) multiplied by AME of the path from health to life satisfaction (b1) i.e:

$$
\text { Indirect effect }(\text { health })=A M E_{\alpha_{1}} * A M E_{b_{1}}
$$

Indirect effects for all paths will be estimated following the same method.

Step 5: The direct effect will be estimated following step 2. The predictor will be the same education or $E D U$, instead of ' $a$ ' we will use the estimate of direct path c'. So AME for c' can be written as:

$$
A M E_{\text {direct effect }}=A M E_{c^{\prime}}=\frac{1}{n} \sum_{i=1}^{n} f\left(c^{\prime} E D U\right)
$$

where c' is an estimate of the direct path estimated by utilizing equation 2 .

$$
A M E_{\text {direct effect }}=\frac{1}{n} \Sigma_{i=1}^{n} \frac{f\left(c^{\prime} E D U_{1}-f\left(c^{\prime} E D U_{2}\right)\right.}{2 h}
$$

whereas $c^{\prime} E D U_{1}$ will be expanded following the matrix given in equation 8 , replacing ' $a$ ' with c' and along with age and age square, all mediating factors

Business Review: (2020) 15(2):1-26 
will also be included in the matrix. Same is true for $c^{\prime} E D U_{2}$.

Step 6: After estimating all indirect and direct effects the next step is to calculate the bootstrapping confidence intervals with 5000 replications in order to check the significance of estimates. All estimations and calculations are done by using $\mathrm{R}$ software and utilizing the 'Marginal Mediation' package developed by Barrett (2018).

\subsection{Data}

The analysis is based on the latest survey data available by the World Values Survey (WVS), Wave 6 (2010-2014). In this survey, 1200 individuals from Pakistan were interviewed. Life satisfaction (LS), Scale of income, freedom of choice that are measured on a 10 point scale, 1 for lower value to 10 the highest are used as they are given in the survey. Health variable is measured on a fourpoint scale, we re-coded the variable and gave number 4 to very good health, 3 to good, 2 to fair and 1 to poor health. Health values were found missing for 6 observations so these observations were excluded from the analysis. Marital status (MS) is also re-coded in our study and 0 is assigned for single and 1 to married people, 23 observations were excluded that reported widowed, divorced or separated as their marital status. Employment status variable is also modified according to the needs of our study, taking this variable as a binary variable, stating 0 for unemployed and 1 for employed. Number of children variable is also used in the analysis which provides information on how many children the respondent has.

Total of 1171 observations are used in the study. The information about age and gender is also derived from the survey. 612 respondents were male while 559 were female out of total 1171 observations that are used in the study. When data is grouped into three categories rich, poor and middle class, we have 214 observations for rich, 733 for the middle class and 224 for poor. Table 1 shows the summary statistics of the data used in the study are discussed below.

Table 1: Descriptive statistics

\begin{tabular}{lcccc}
\hline & Min & Max & Mean & S.D \\
\hline Life satisfaction & 1 & 10 & 7.49 & 2.1 \\
Health & 1 & 4 & 3.1 & 0.838 \\
Freedom & 1 & 10 & 7.29 & 2.143 \\
Marital status & 0 & 1 & 0.75 & 0.436 \\
Number of children & 0 & 8 & 2.26 & 2.044 \\
Scale of income & 1 & 10 & 5.52 & 2.128 \\
Employment status & 0 & 1 & 0.36 & 0.481 \\
Education & 1 & 9 & 4.04 & 2.245 \\
Age & 18 & 85 & 34.08 & 11.56 \\
\hline
\end{tabular}




\section{Estimation results}

Section 4 reports and explains the estimation results of the impact of education on life satisfaction. This section is divided into four sub-sections. Section 4.1 reports the estimation results using the full sample. Section 4.2 reports the gender wise analysis. Section 4.3 reports the result for data divided into three categories, poor, rich and middle class based on the income scale.

\subsection{Results of impact of education on life satisfaction (Full data)}

In order to analyze the impact of education on life satisfaction, the first step is to calculate the impact of education on the potential mediators identified in the model. Table 2 reports the impact of education on the mediating factors of the model that are health, freedom of choice, marital status, number of children, employment status and scale of income. In standard notations we call it 'a' paths. The results are for full data containing 1171 observations, and all regressions are controlled for age and age square.

The results in table 2 show that there is a significant impact of education on all mediating factors. The results demonstrate a positive significant impact of education on health, freedom of choice, employment status and scale of income while a negative impact on the number of children and marital status. The strongest positive impact of education is on the scale of income. Marital status and employment status are included in binary form, so the coefficients are showing the probability of getting married or employed. The results are showing that with an increase in education level, the probability of getting employed increases, while the probability of getting married decreases. The negative sign of the number of children coefficient is giving the information that with an increase in the level of education on average people have fewer children, which is as expected and observed.

Powdthavee et al (2015) observed the positive and significant impact of education on health, income, employment status, getting married but a significant and negative impact on the number of children in the case of Australia. So current study reports same signs of coefficients of 'a' paths except for marital status which is positive in case of Australia in the study of Powdthavee et al (2015) but negative in case of Pakistan.

After finding the 'a' paths, the next step in mediation analysis is to find the impact of predictor and mediators on the outcome variable (i.e. c' and b paths). So in order to calculate the direct effect and to see the impact of mediators on life satisfaction, equation 2 in section 3 is estimated including all mediators and education as a predictor. The results are summarized in table 3 . The results show that the impact of education, health, freedom and scale of income on life satisfaction are positive and highly significant while the impact of the number of children and employment status are found highly insignificant. The impact of marital status is also insignificant but its p-value is 0.11 . The most powerful and significant impact is of health on life satisfaction, while freedom of choice and scale of income are 2nd and 3rd dominant factors having a positive impact

Business Review: (2020) 15(2):1-26 
Table 2: Impact of education on mediators(a paths)

\begin{tabular}{lccc}
\hline Mediator & Education & Age & Age square \\
\hline Health & 0.0420 & -0.0148 & 0.0001 \\
& $(0.0002)$ & $(0.1671)$ & $(0.3253)$ \\
Freedom & 0.1480 & 0.0169 & 0.0000 \\
& $(0.0000)$ & $(0.5382)$ & $(0.9331)$ \\
Marital status & -0.2913 & 0.6243 & -0.0059 \\
& $(0.0000)$ & $(0.0000)$ & $(0.0000)$ \\
No. of children & -0.1213 & 0.2803 & -0.0023 \\
& $(0.0000)$ & $(0.0000)$ & $(0.0000)$ \\
Employment status & 0.1798 & 0.1105 & -0.0009 \\
& $(0.0000)$ & $(0.0001)$ & $(0.0144)$ \\
Scale of income & 0.2375 & 0.0076 & -0.0001 \\
& $(0.0000)$ & $(0.7773)$ & $(0.8141)$ \\
\hline
\end{tabular}

* p-values are given in parenthesis

* Estimations are done through glm and the binomial link is used where the mediators are binary.

on life satisfaction.

Powdthavee et al (2015) found that all effects from mediators to life satisfaction are highly significant and positive except for the direct effect of education (c') which have a negative sign in the study and found highly significant. In contrast to their study, we find number of children and employment status insignificant. Another notable difference is that they found c' negative while we have positive and significant coefficient for c' path.

Table 3: Impact of education and mediating factors on LS (c' and b paths)

\begin{tabular}{lcc}
\hline Path & Coefficient & p-value \\
\hline Education (c') & 0.0735 & 0.0038 \\
Health & 0.6861 & 0.0000 \\
Freedom & 0.3720 & 0.0000 \\
Marital status & -0.2798 & 0.1154 \\
No. of children & 0.0005 & 0.9885 \\
Employment status & -0.0959 & 0.3918 \\
Scale of income & 0.1314 & 0.0000 \\
Age & -0.0133 & 0.6281 \\
Age Square & 0.0001 & 0.6671 \\
\hline
\end{tabular}

Note: Estimation results of glm where life satisfaction was the dependent variable

\subsubsection{Indirect effects}

The main purpose of the study is to test the channels through which education affects life satisfaction. Six mediators are chosen to find the paths between education and life satisfaction. The method of marginal mediation was followed proposed by Barrett (2018). Under this approach, all the mediating effects are reported in Average Marginal Effects (AME), therefore they are comparable with each other irrespective of the type of mediator; whether the mediator is 
binary, count or continuous. So the coefficient of marital status and employment status are comparable with health and freedom of choice that are non-binary.

Table 4 shows the indirect effects, they are reported in the form of AMEs and are in the outcome's metric. AME shows the change in outcome expressed in the outcome's units due to one unit change in the predictor. Health, freedom of choice and control over life and scale of income are found positive and significant mediators in education and life satisfaction relationship, while marital status, number of children and employment status are found insignificant. Comparison of the coefficients of significant mediators shows that the indirect impact of education on life satisfaction is stronger through the channel of freedom of choice and control over life than health and scale of income. The second powerful impact is through the scale of income and then through health. Although results reported in table 4 are for a $95 \%$ confidence interval, the results of $90 \%$ bootstrapping C-I implies the same decision about the significance of indirect effects. If we add up all the significant indirect effects the total indirect effect is 0.11503 .

Table 4: Indirect effects of education on life satisfaction

\begin{tabular}{lccc}
\hline Mediator & \multicolumn{3}{c}{ Mediated effects } \\
\hline & Coefficient & Confidence interval \\
\hline Health & $0.02879^{* *}$ & 0.01254 & 0.04663 \\
Freedom & $0.05504^{* *}$ & 0.03242 & 0.07996 \\
Marital status & 0.00689 & -0.00170 & 0.01588 \\
No. of children & -0.00006 & -0.00935 & 0.00991 \\
Employment status & -0.00372 & -0.01268 & 0.00475 \\
Scale of income & $0.03120^{* *}$ & 0.01667 & 0.04675 \\
\hline
\end{tabular}

** shows significance based on $95 \%$ C-I (calculated through bootstrapping technique with 5000 replications)

\subsubsection{Direct effects}

The direct effect of education is reported in table 5 and shows that the direct path is positive and significant at $5 \%$ level of significance. It is noticed that the direct effect is significant and larger than the individual indirect effect. However, it is less than the total indirect effect (i.e. 0.11503, the sum of significant indirect effect). Moreover, it is realized that the model is a partial mediation model because the introduction of mediators does not reduce the direct path to zero or does not make it insignificant. If we compare our study with Powdthavee et al (2015) then our results are different in respect of direct path, as their study reports negative direct effect and they also find this path significant.

Finally, it is observed in the analysis of a full sample that health, freedom of choice and scale of income are significant and positive mediators in the relationship between education and life satisfaction, while marital status, number of children and employment status are found to have insignificant indirect effect. The direct effect is positive and significant. It is greater than individual direct effect but less than the total indirect effect.

Business Review: (2020) 15(2):1-26 
Table 5: Direct effect of education on life satisfaction

\begin{tabular}{llll}
\hline & Coefficient & Confidence interval \\
\hline Direct effect of education & $0.07352^{* *}$ & 0.02102 & 0.12443 \\
\hline Note: $95 \%$ Confidence interval is calculated through bootstrap- \\
ping technique with 5000 replications $* *$ \\
are sign shows that effects \\
aricant at $5 \%$ level of significance
\end{tabular}

4.2 Gender differences in the impact of education on life satisfaction

In order to see how differently mediating factors work for male and female in the relationship between education and life satisfaction, the data is divided into two distinct groups based on gender. The sub-sample of females contains 559 observations while sub-sample of the males have 612 observations. All regressions are controlled for age and age squared. The results of the impact of education on mediators ('a' paths) are provided in table 6.

While comparing the paths from education to mediating factors it can be seen that effect of education on all mediating factors are stronger for females than males except its impact on the scale of income, which is higher for males as compared to females. These results give some interesting insights, such as an increased level of education for women means a more positive impact on their health as compared to men. Similarly, higher education contributes more to the freedom of choice and control over the life of women than for men.

If we compare the coefficients of marital status for two groups there is a greater negative impact of education for women than for men in terms of getting married. Similarly, the results show that on average educated females have fewer children as compared to educated men. The results of employment status show that education as a predictor of employment status is insignificant for males. The reason might be that in the case of Pakistan men have to earn a livelihood and get employment whether they are educated or not. On the other hand, coefficient of employment status for females is significant and positive which shows that with an increased level of education there are more chances for a female to get employed or women with a low level of education are not encouraged to get employed. The effect of education to influence the scale of income is higher for men as compared to females and positive and significant for both.

Table 7 shows the direct effect of education on life satisfaction as well as the impact of mediating factors on life satisfaction for both males and females. 'b' paths from health and freedom are found significant and positive for both genders. However, the coefficient of health is much higher for males while the coefficient of freedom is much higher for females. It implies that on average males give more importance to their health in describing their life satisfaction and need to be healthier in order to feel satisfied in their lives as compared to females. On the other hand, females give more weight to their freedom and control over life, they acknowledge their ability to choose and act freely more than men and feel more satisfied in their lives if they have more freedom. Gender differences are also found in results for the scale of income, where for males the scale of income in explaining life satisfaction is highly significant, while for 
Education and life satisfaction...

Table 6: Genderwise effect of education on mediators (a paths)

\begin{tabular}{lcccc}
\hline Mediator & \multicolumn{2}{c}{ Male } & \multicolumn{2}{c}{ Female } \\
\hline & Coefficient & p-value & Coefficient & p-value \\
\hline Health & 0.0358 & 0.0267 & 0.0576 & 0.0008 \\
Freedom & 0.0516 & 0.1885 & 0.1114 & 0.0095 \\
Marital status & -0.2562 & 0.0002 & -0.3263 & 0.0000 \\
No. of children & -0.0853 & 0.0025 & -0.1439 & 0.0000 \\
Employment status & -0.0397 & 0.3436 & 0.4937 & 0.0001 \\
Scale of income & 0.2835 & 0.0000 & 0.2442 & 0.0000 \\
\hline
\end{tabular}

Note: Estimations are done through glm and the binomial link is used where the mediators are binary. $\mathrm{n}=612$ for male and $\mathrm{n}=559$

females the coefficient value is much lower. It is also observed that number of children and employment status are not significant for both men and women in life satisfaction regression.

Moreover, for men, the marital status coefficient is negative and significant showing that married men generally have less satisfaction as compared to unmarried men. For women, marital status is found insignificant in defining life satisfaction. The estimation of both ' $a$ ' and ' $b$ ' paths are done through generalized linear models and the binomial link is used where the mediator is binary.

Table 7: Impact of education and mediating factors on LS (c' and b paths)

\begin{tabular}{lcccc}
\hline & \multicolumn{2}{c}{ Male } & \multicolumn{2}{c}{ Female } \\
\hline & Coefficient & p-value & Coefficient & p-value \\
\hline Education (c) & 0.0768 & 0.0304 & 0.0665 & 0.0715 \\
Health & 0.8280 & 0.0000 & 0.5536 & 0.0000 \\
Freedom & 0.2380 & 0.0000 & 0.5344 & 0.0000 \\
Marital Status & -0.5299 & 0.0434 & -0.2005 & 0.4168 \\
No. of Children & -0.0274 & 0.5868 & 0.0432 & 0.4032 \\
Employment Status & -0.0675 & 0.6803 & -0.2016 & 0.6831 \\
Scale of Income & 0.1797 & 0.0000 & 0.0517 & 0.1458 \\
Age & 0.0316 & 0.4099 & -0.0564 & 0.1695 \\
Age Square & -0.0003 & 0.5059 & 0.0006 & 0.2439 \\
\hline
\end{tabular}

Note: Estimation results of glm where Life satisfaction was the dependent variable

\subsubsection{Comparison of gender differences in mediated effects}

Table 8 shows the results of indirect effect for males and females separately along with a $95 \%$ confidence interval that helps in comparison of gender-based differences in the effect of education on life satisfaction. The strongest indirect effect of education on life satisfaction for a male is through the scale of income, while for females it is through freedom of choice and control over life. For men health, marital status and scale of income are significant at $5 \%$ level of significance, while freedom, number of children and employment status are 
F. Hassan et. al

Table 8: Comparison of indirect effect of education for males and females

\begin{tabular}{lcrcccc}
\hline & \multicolumn{3}{c}{ Male } & \multicolumn{3}{c}{ Female } \\
\hline Mediator & Effect & \multicolumn{2}{c}{ C-I } & Effect & \multicolumn{2}{c}{ C-I } \\
\hline Health & $0.02962^{* *}$ & 0.00300 & 0.05997 & $0.03188^{* *}$ & 0.0118 & 0.05467 \\
Freedom & 0.01228 & -0.00725 & 0.03401 & $0.05951^{* *}$ & 0.01154 & 0.10964 \\
Marital status & $0.00954^{* *}$ & 0.00028 & 0.02094 & 0.00622 & -0.009 & 0.0221 \\
No. of children & 0.00234 & -0.00810 & 0.01435 & -0.00622 & -0.02159 & 0.00681 \\
Employment status & 0.00055 & -0.00373 & 0.00517 & -0.00199 & -0.00892 & 0.00397 \\
Scale of income & $0.05094^{* *}$ & 0.02731 & 0.07792 & 0.01262 & -0.00658 & 0.03444 \\
\hline
\end{tabular}

Note: $95 \%$ Confidence interval through Bootstrapping is reported in the table however same decision regarding significance remains at $10 \%$ significance level. ${ }^{* *}$ sign shows that effects are significant at $5 \%$ level of significance

found insignificant even at $10 \%$ level of significance. The reason for rejection of freedom as a mediator between education and life satisfaction is that the effect of freedom on life satisfaction is significant but freedom for men is not caused by education, because the path from education to freedom is insignificant.

Employment status does not play a mediating role between education and life satisfaction, ' $a$ ' and 'b' paths associated with employment status both are insignificant for men, and hence employment status is not a mediating factor. Education has a significant and negative impact on number of children for men but the 'b' path is insignificant, i.e. men do not give significant weight to the number of children in defining life satisfaction. So the number of children is not found as a mediator between education and life satisfaction.

For women, only health and freedom are significant mediators between education and life satisfaction. It is interesting to note that all the 'a' paths are highly significant, showing a positive effect of education on health, freedom, the scale of income and employment status and negative on marital status and number of children. But this effect does not lead to a higher level of life satisfaction because only ' $b$ ' path through health and freedom is significant and all other 'b' paths are insignificant.

Comparison with Powdthavee et al (2015) shows that we have some different results, their study found all indirect effects that are health, marital status, number of children, income and employment positive and significant for men while in this study for Pakistan the indirect effects of health, scale of income and marital status are positive and significant. Similarly, for women, the study of Powdthavee et al (2015) has reported that all effects are significant except for employment. If we compare our results then it can be seen that only two channels freedom of choice and health are significant for women in Pakistan and all other channels are found insignificant.

\subsubsection{Comparison of gender-based differences in direct effects}

The results for direct effects of education on life satisfaction are provided in table 9 . The direct effect of education for men is slightly higher than the direct effect of education on life satisfaction for women. The indirect paths are not significant at $5 \%$ level of significance but become significant at $10 \%$ level of 
significance.

Summing up, it is found that the impact of education translates into life

Table 9: Direct effect of education on life satisfaction

\begin{tabular}{lcccc}
\hline Direct effect & Coefficient & \multicolumn{3}{c}{ Confidence interval } \\
\hline Male & $0.07677^{*}$ & -0.00143 & 0.15508 & $95 \%$ \\
& & 0.00980 & 0.14100 & $90 \%$ \\
Female & $0.06654^{*}$ & -0.00786 & 0.14482 & $95 \%$ \\
& & 0.00179 & 0.13166 & $90 \%$ \\
\hline
\end{tabular}

Note: Confidence interval is calculated through bootstrapping technique with 5000 replications * shows that effects are significant at $10 \%$ level of significance

satisfaction differently for men and women. Channels of the scale of income, health and marital status are significant for men while for women, freedom of choice and health are significant mediators. If we add up all the significant indirect effect for men its total is 0.0901 and for women it is 0.0914, implying that both have almost the same total indirect effect, while the direct effect of education is slightly higher for men (0.0767) than for women (0.0665).

4.3 Difference in effect of education on life satisfaction on the basis of scale of income

In the world values survey, the scale of income consists of 10 different levels. To analyze the possible differences in the role of education in life satisfaction for poor, middle class and rich we have divided the data into three different segments. The first group which refers to poor in our study consist of all observations who listed themselves in the lowest 3 scales out of 10 . The rich refers to the people falling in the upper three scales i.e. 8,9 and 10. While the middle class is constituted by combining all observations which are in 4, 5, 6 and 7 scales in the scale of income variable. Table 10 shows the results of all three groups i.e. poor, middle class and rich which gives information on estimated coefficient values and their significance for each path that goes from education to mediating factors.

It is found that the impact of education on health is significant in the case of the poor and middle class but it is highly insignificant for rich even at $10 \%$ level of significance. The impact of education on freedom of choice is highly significant in the case of the middle class while this path is insignificant in the case of poor and rich. It implies that the increased level of education increases the ability of individuals living in the middle class to choose and make their decisions freely. For poor, increased level of education does not mean a higher level of freedom. The insignificant effect of education on freedom for the rich might be because the freedom of the rich might not depend on the level of education.

Marital status is a binary variable and the coefficients associated with this variable given in table 10 are in the form of probability. The results show that 
Table 10: Results for effect of education on mediators (a paths)

\begin{tabular}{lccc}
\hline Mediator & Rich & Middle class & Poor \\
\hline Health & 0.0038 & 0.0336 & 0.0531 \\
& $(0.8726)$ & $(0.0218)$ & $(0.0785)$ \\
Freedom & -0.0516 & 0.1863 & 0.0313 \\
& $(0.3782)$ & $(0.0000)$ & $(0.7218)$ \\
Marital status & -0.1757 & -0.2791 & -0.5775 \\
& -0.1176 & 0.0000 & -0.0001 \\
No. of children & -0.0775 & -0.0967 & -0.2301 \\
& $(0.0881)$ & $(0.0003)$ & $(0.0000)$ \\
Employment status & 0.2430 & 0.2005 & 0.0839 \\
& $(0.0006)$ & $(0.0000)$ & $(0.2493)$ \\
\hline
\end{tabular}

Note: Estimations are done through glm and the binomial link is used where the mediators are binary. Number of observations for Rich, Middle class and poor are 214, 733 and 224. * p-values are given in parenthesis

an increase in education decreases the probability of getting married. The impact of education in all three cases is significant, with highest negative impact for poor then for the middle class and smaller for rich with significance level dropping down to $11 \%$ from highly significant coefficients for the middle class and poor. Impact of education on number of children is negative and significant for all income classes, meaning that people with higher education on average have fewer children. The coefficient is higher in case of poor, middle class have the lesser impact of education on the number of children as compared to the poor class and people in the rich class also have this path significant but the effect is less than the middle and poor class.

The impact of education on employment status is highly significant and positive in case of the middle class and rich but it is insignificant in case of poor. The results are very much evident of the prevailing conditions in developing countries like Pakistan where poor face more difficulty in finding employment and improving employment status as compared to middle and rich class and that's why the results show that increasing education is not enough to get employment for poor and so the coefficient showing impact of education for poor on employment status is found insignificant.

Table 11 shows the impact of potential mediators on life satisfaction and their respective p-values. While analyzing paths from mediating factors to life satisfaction, it is found that health and freedom of choice have a highly significant and positive impact on life satisfaction for all three categories. The results also show that marital status has a significant positive effect in case of poor, significant negative effect in the case of the middle class and insignificant effect in case of rich on life satisfaction. The results imply that for poor, being married increases the chances of being satisfied in life, while for the middle class on average the married people report less satisfaction then unmarried. However, for rich, this path is insignificant implying that for the rich class marital status does not play any role in life satisfaction.

The results indicate that the number of children have a negative impact on life satisfaction in case of poor and significant at $10 \%$ significance level. For 
middle class, the effect of number of children on life satisfaction is positive and significant while for rich it is insignificant. Comparison of employment status coefficients tells us that employment status is insignificant in defining life satisfaction for the rich and middle class while for poor it is significant and its effect is negative implying that the probability of being satisfied in life decreases if the person in the poor class is employed.

Table 11: Effect of education on mediators on life satisfaction (c' and b paths)

\begin{tabular}{lccc}
\hline Path & Rich & Middle class & Poor \\
\hline Education (c') & 0.0173 & 0.0415 & 0.1943 \\
& $(0.7343)$ & $(0.1637)$ & $(0.0135)$ \\
Health & 0.7749 & 0.5392 & 0.9811 \\
& $(0.0000)$ & $(0.0000)$ & $(0.0000)$ \\
Freedom & 0.2850 & 0.4428 & 0.2809 \\
& $(0.0000)$ & $(0.0000)$ & $(0.0000)$ \\
Marital status & -0.4077 & -0.7770 & 1.4981 \\
& $(0.2803)$ & $(0.0002)$ & $(0.0057)$ \\
No. of children & -0.0410 & 0.0828 & -0.1680 \\
& $(0.6078)$ & $(0.0515)$ & $(0.0909)$ \\
Employment status & -0.0915 & 0.0688 & -0.6121 \\
& $(0.6942)$ & $(0.6099)$ & $(0.0509)$ \\
\hline
\end{tabular}

Note: Estimations are done through glm. p-values are given in parenthesis

\subsubsection{Mediated effects for different income classes}

Comparing the indirect effect of education on life satisfaction among different income classes, it is found that for poor, channels of health is significant at $10 \%$ level of significance while marital status is significant at $5 \%$. All other paths for the poor are found insignificant. In the case of the middle class all channels that are of health, freedom of choice and marital status and number of children are significant at $5 \%$ level of significance except the channel of employment status.

It is thought-provoking to note that all the indirect effects are found insignificant in the case of the rich class, implying that none of the underlying factors are bridging the effect of education and life satisfaction for rich people.

\subsubsection{Comparison of direct effect for different income classes}

The results of direct effect reported in table 13 show that for rich the direct effect is insignificant even at $10 \%$ level of significance. For the middle class, the direct effect becomes insignificant as the effect of education is translated through the significant indirect effect. It is important to note that for poor the direct effect is significant at $5 \%$ level of significance and it has a large coefficient value which means that there is a strong impact of education on life satisfaction of poor. 
Table 12: Mediated effects of education on life satisfaction for poor, middle class and rich

\begin{tabular}{lccc}
\hline & \multicolumn{3}{c}{ Indirect effects } \\
\hline Mediator & Rich & Middle class & Poor \\
\hline Health & 0.0029 & $0.01814^{* *}$ & $0.05209^{*}$ \\
Freedom & -0.0147 & $0.08251^{* *}$ & 0.0088 \\
Marital status & 0.0055 & $0.01970^{* *}$ & $-0.05562^{* *}$ \\
No. of children & 0.0032 & $-0.00801^{* *}$ & 0.0387 \\
Employment status & -0.0051 & 0.0028 & -0.0115 \\
\hline
\end{tabular}

Note: ${ }^{* *}$ shows significance based on $95 \%$ C-I through bootstrapping with 5000 replications $*$ shows significance based on 90\% C-I through bootstrapping with 5000 replications

Table 13: Direct effect of education of life satisfaction

\begin{tabular}{lcrrr}
\hline Direct effect & Coefficient & \multicolumn{3}{c}{ Confidence interval } \\
\hline Rich & 0.01726 & -0.10936 & 0.13543 & $95 \%$ \\
& & -0.08638 & 0.11532 & $90 \%$ \\
Middle class & 0.04145 & -0.02197 & 0.10381 & $95 \%$ \\
& & -0.01117 & 0.09473 & $90 \%$ \\
Poor & $0.19432^{* *}$ & 0.04235 & 0.33702 & $95 \%$ \\
& & 0.06702 & 0.31094 & $90 \%$ \\
\hline
\end{tabular}

Note: Confidence interval is calculated through bootstrapping technique. $* *$ shows that effects are significant at $5 \%$ level of significance

Summing up, the analysis of the impact of education on life satisfaction for rich, middle and poor class, it can be concluded that indirect effects are stronger and significant in case of the middle class than poor and are insignificant in case of the rich. For the middle class, health, freedom, marital status, number of children are significant and only employment status is found insignificant. In the case of poor, health and marital status are significant and freedom, the number of children and employment status are found insignificant. For rich all the paths are found insignificant. In case of direct effect, the strongest direct effect is for poor (0.1943) and it is also significant. For the middle class, the direct effect is found to be insignificant and the value (0.0415) is quite small as compared to the direct effect for the poor. For rich, the direct path is also insignificant and the smallest of all (0.0173).

\section{Conclusion}

The following conclusions can be drawn based on analysis done and reported in section 4.

It is observed that education plays a significant role in affecting the life satisfaction of individuals in Pakistan. Health, freedom and scale of income are found significant mediators in the analysis of the full sample. In addition, the direct effect is significant and positive. It implies that the mediation model is a partial mediation model as the introduction of mediators does not make the direct path insignificant. 
When the sample is divided into two groups on the bases of gender, it is found that the impact of education takes different paths in life satisfaction of males and females. For men, the channels of the scale of income, health and marital status while for women, freedom of choice and health are found significant. For men, the strongest effect of education on life satisfaction is through the scale of income and for women it is through freedom of choice. The total indirect effect of education for women is slightly higher than for men. The direct effect for males and females both are significant at $10 \%$ level of significance.

The analysis of the impact of education on life satisfaction based on the scale of income illustrates that as compared to rich and poor more channels are effective for the middle class. It is found that all indirect effects, as well as the direct effects, are insignificant in case of the rich, which means the role of education in defining and affecting the life satisfaction of rich is not supported by the data and is found insignificant. It means that in the case of Pakistan the upper class does not significantly value education in explaining their life satisfaction. On the other hand, for the middle class, all of the indirect effects are significant except employment status. This implies that the level of education is playing a crucial role in improving life satisfaction of people belonging to the middle class. The direct path between education and life satisfaction for the middle class is also effective. For poor class, although only health and marital status are significant mediating effects, the coefficient of direct effect is 0.1943 which shows a much higher value as compared to the direct path of the middle class. It means that although most of the indirect effects like freedom of choice, number of children and employment status channels are insignificant still education has the ability to affect the life satisfaction of poor through its direct effect.

\section{Implications and ideas for future research}

The study of the impact of education on life satisfaction has the following policy implications. It identifies and tests the direct and indirect effect of education on the life satisfaction of individuals in Pakistan for the first time. It helps in identifying the channels that are operative between education and life satisfaction and ones that are broken. For example, the analysis of the full sample tells us that the channel of employment status is insignificant between education and life satisfaction. Deeper look in the matter tells us that the path from education to employment status is significant and positive. But the path from employment status to life satisfaction is broken or is found insignificant. It means that education is increasing the probability of getting employed but then the broken path between employment and life satisfaction hinders the effect of education to transfer to life satisfaction. Further research and policy intervention is required to mend this broken path.

Similarly, in the case of females, it is observed that only two channels, health and freedom of choice are significant. The results show that all the paths from education to mediators are significant and operative but most of the paths from these mediators to life satisfaction are not effective or are insignificant. As a result only health and freedom of choice are found to be significant mediators 
for women. The broken paths must be mended to fully reap the benefits of education in the country.

The health channel is found to be significant in case of every model in our study that is a full sample, male or female, middle class or poor except for rich. This gives guidelines to both health and education policymakers, that the good of education is effectively translating to health and then to the life satisfaction of individuals. Therefore, the policy of increased education will also lead to increased health in the country.

The analysis of impact of education for different income classes that is rich, poor and middle class shows that there is significant role of education in impacting life satisfaction of poor and middle class, therefore policies should be designed to increase the level of education of poor and middle class to increase the level of life satisfaction in the country. Although, the current study is first of its kind for Pakistan and identifies the broken links between education and life satisfaction the research gap remains to find the reasons of broken links between education and life satisfaction in Pakistan. Research is also needed to formulate appropriate policies to address these issues.

\section{References}

Albert C, Davia MA (2005) Education, wages and job satisfaction. In: Epunet conference

Angrist JD, Keueger AB (1991) Does compulsory school attendance affect schooling and earnings? The Quarterly Journal of Economics 106(4):979-1014

Appleton S, Song L (2008) Life satisfaction in urban china: Components and determinants. World Development 36(11):2325-2340

Baron RM, Kenny DA (1986) The moderator-mediator variable distinction in social psychological research: Conceptual, strategic, and statistical considerations. Journal of personality and social psychology 51(6):1173

Barrett TS (2018) Marginal mediation analysis: A new framework for interpretable mediated effects. PhD thesis, UTAH STATE UNIVERSITY

Bartus T (2005) Estimation of marginal effects using margeff. The Stata Journal 5(3):309-329

Blanchflower DG, Oswald AJ (1994) Estimating a wage curve for britain 1973-90. The Economic Journal 104(426):1025-1043

Blanchflower DG, Oswald AJ (2004) Well-being over time in britain and the usa. Journal of public economics 88(7-8):1359-1386

Botha F (2014) Life satisfaction and education in south africa: Investigating the role of attainment and the likelihood of education as a positional good. Social Indicators Research $118(2): 555-578$

Brighouse H (2006) On education. Routledge

Bukenya JO, Gebremedhin TG, Schaeffer PV (2003) Analysis of quality of life and rural development: Evidence from west virginia data. Growth and Change 34(2):202-218

Campbell A (1981) The sense of well-being in America: Recent patterns and trends

Ferrer-i Carbonell A (2005) Income and well-being: an empirical analysis of the comparison income effect. Journal of public economics 89(5-6):997-1019

Card D (1999) The causal effect of education on earnings. In: Handbook of labor economics, vol 3, Elsevier, pp 1801-1863

Castriota S (2006) Education and happiness: A further explanation to the easterlin paradox?

Checchi D (2006) The economics of education: Human capital, family background and inequality. Cambridge University Press

Chen Wc (2012) How education enhances happiness: Comparison of mediating factors in four east asian countries. Social indicators research 106(1):117-131

Chiappori PA, Iyigun M, Weiss Y (2009) Investment in schooling and the marriage market. American Economic Review 99(5):1689-1713 
Clark AE, Oswald AJ (1996) Satisfaction and comparison income. Journal of public economics 61(3):359-381

Cuñado J, de Gracia FP (2012) Does education affect happiness? evidence for spain. Social indicators research 108(1):185-196

Cutler DM, Lleras-Muney A (2006) Education and health: evaluating theories and evidence. Tech. rep., National bureau of economic research

Dockery AM, et al (2003) Happiness, life satisfaction and the role of work: Evidence from two Australian surveys. School of Economics and Finance, Curtin University of Technology

Easterlin RA (2004) Life satisfaction: Can we produce it? In: Challenges for Quality of Life in the Contemporary World, Springer, pp 347-357

Ferrante F (2009) Education, aspirations and life satisfaction. Kyklos 62(4):542-562

Frey BS, Stutzer A (2000) Happiness, economy and institutions. The Economic Journal 110(466):918-938

Gerdtham UG, Johannesson M (2001) The relationship between happiness, health, and socioeconomic factors: results based on swedish microdata. The Journal of Socio-Economics 30(6):553-557

Grün C, Hauser W, Rhein T (2010) Is any job better than no job? life satisfaction and reemployment. Journal of Labor Research 31(3):285-306

Haller M, Hadler M (2006) How social relations and structures can produce happiness and unhappiness: An international comparative analysis. Social indicators research 75(2):169216

Harmon C, Walker I (1995) Estimates of the economic return to schooling for the united kingdom. The American Economic Review 85(5):1278-1286

Hassall EJ, Muller JJ, Hassall SL, et al (2004) Working towards ill health?: An investigation of psychological well-being in unemployed and employed low-wage earners. International Journal of Employment Studies 12(2):73

Hayo B, Seifert W (2003) Subjective economic well-being in eastern europe. Journal of economic psychology 24(3):329-348

Headey B, Wooden M (2004) The effects of wealth and income on subjective well-being and ill-being. Economic record 80:S24-S33

Headey B, Muffels R, Wooden M (2008) Money does not buy happiness: Or does it? a reassessment based on the combined effects of wealth, income and consumption. Social Indicators Research 87(1):65-82

Helliwell JF (2003) How's life? combining individual and national variables to explain subjective well-being. Economic modelling 20(2):331-360

Inglehart R, Klingemann HD (2000) Genes, culture, democracy, and happiness. Culture and subjective well-being pp 165-183

Inglehart R, Foa R, Peterson C, Welzel C (2008) Development, freedom, and rising happiness: A global perspective (1981-2007). Perspectives on psychological science 3(4):264-285

Judd CM, Kenny DA (1981) Process analysis: Estimating mediation in treatment evaluations. Evaluation review 5(5):602-619

Kettunen J (1997) Education and unemployment duration. Economics of education review 16(2):163-170

Lafortune J (2013) Making yourself attractive: Pre-marital investments and the returns to education in the marriage market. American Economic Journal: Applied Economics 5(2):15178

Layard R (2004) Good jobs and bad jobs

Layard R, Clark A, Cornaglia F, Vernoit J, Powdthavee N (2013) What predicts a successful life? a life-course model of well-being (iza discussion paper, no. 7682)

Leigh A, Ryan C (2008) Estimating returns to education using different natural experiment techniques. Economics of Education Review 27(2):149-160

MacKinnon DP, Dwyer JH (1993) Estimating mediated effects in prevention studies. Evaluation review 17(2):144-158

Martin TC (1995) Women's education and fertility: results from 26 demographic and health surveys. Studies in family planning pp 187-202

Michalos AC (2008) Education, happiness and wellbeing. Social Indicators Research 87(3):347-366

Mincer J (1991) Education and unemployment. Tech. rep., National Bureau of Economic Research 
Mincer JA (1974) Schooling and earnings. In: Schooling, experience, and earnings, NBER, pp $41-63$

Oreopoulos P, Salvanes KG (2011) Priceless: The nonpecuniary benefits of schooling. Journal of Economic perspectives 25(1):159-84

Powdthavee N (2010) Does education reduce the risk of hypertension? estimating the biomarker effect of compulsory schooling in england. Journal of Human Capital 4(2):173202

Powdthavee N, Lekfuangfu WN, Wooden M (2015) What's the good of education on our overall quality of life? a simultaneous equation model of education and life satisfaction for australia. Journal of behavioral and experimental economics 54:10-21

Psacharopoulos G, Patrinos HA (2018) Returns to investment in education: a decennial review of the global literature. The World Bank

Rojas M (2004) Well-being and the complexity of poverty: A subjective well-being approach. 2004/29, WIDER Research Paper

Sander W (1992) The effect of women's schooling on fertility. Economics Letters 40(2):229-233

Scitovsky T (1976) The joyless economy: An inquiry into human satisfaction and consumer dissatisfaction.

Selim S (2008) Life satisfaction and happiness in turkey. Social Indicators Research 88(3):531562

Shin DC, Inoguchi T (2009) Avowed happiness in confucian asia: Ascertaining its distribution, patterns, and sources. Social Indicators Research 92(2):405-427

Shrout PE, Bolger N (2002) Mediation in experimental and nonexperimental studies: new procedures and recommendations. Psychological methods 7(4):422

Silles MA (2009) The causal effect of education on health: Evidence from the united kingdom. Economics of Education review 28(1):122-128

Smith K (2003) Individual welfare in the soviet union. Social Indicators Research 64(1):75-105

Tella RD, MacCulloch RJ, Oswald AJ (2003) The macroeconomics of happiness. Review of Economics and Statistics 85(4):809-827

Veenhoven R (1996) Happy life-expectancy. Social indicators research 39(1):1-58

Veenhoven R (2012) Happiness: Also known as life satisfaction and subjective well-being. In: Handbook of social indicators and quality of life research, Springer, pp 63-77

Verme P (2009) Happiness, freedom and control. Journal of Economic Behavior \& Organization $71(2): 146-161$

Witter RA, Okun MA, Stock WA, Haring MJ (1984) Education and subjective well-being: A meta-analysis. Educational Evaluation and Policy Analysis 6(2):165-173

Yang Y (2008) Social inequalities in happiness in the united states, 1972 to 2004: An ageperiod-cohort analysis. American sociological review 73(2):204-226 